\title{
Off-Site Storage and Special Collections: A Study in Use and Impact in ARL Libraries in the United States
}

\section{Charlotte Priddle and Laura McCann}

\begin{abstract}
Special collections libraries collect and preserve materials of intellectual and cultural heritage, providing access to unique research resources. As their holdings continue to expand, special collections in research libraries confront increased space pressures. Off-site storage facilities, used frequently by research libraries for general circulating collections, offer a solution to these pressures. Using data from a survey of special collections directors from ARL member libraries, this article examines both the current use of off-site storage facilities and its impact on core special collections activities. This study provides a foundation for what has been an underexplored area and identifies areas for further research.
\end{abstract}

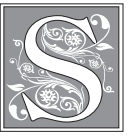

pecial collections libraries are devoted to collecting, organizing, preserving, describing, and providing access to primary source materials across multiple formats. Those currently involved in the profession acquire cultural materials that build on the legacies of the past, support present areas of research, and anticipate the needs of future scholars. Often based within larger institutions, special collections libraries bear responsibility for the preservation and care of their collections and support research by providing access to and use of such materials. ${ }^{1}$

As technologies change and the pace of acquisition increases, special collections libraries confront increased pressures in terms of space, public access needs, and preservation concerns. The formats of the material collected can vary widely within the same collection and can include not only bound volumes of varying age and rarity as well as traditional printed archival material, but also digital and analog media, objects, artworks, photographic media, and ephemera. Such a diversity of formats can radically affect issues of storage, access, preservation, and curation. In the face of these challenges, the off-site storage facilities used by many libraries for circulating collections are increasingly used for the storage of special collections materials. This trend can be controversial, as evidenced in the editorials and letters regarding proposed changes at the main branch of the New York Public Library (NYPL). ${ }^{2}$ These issues are not exclusive to NYPL and are reported in other research libraries. ${ }^{3}$

Charlotte Priddle is Librarian for Printed Books in Fales Library \& Special Collections of New York University Libraries; e-mail: charlotte.priddle@nyu.edu. Laura McCann is Conservation Librarian in the Barbara Goldsmith Preservation \& Conservation Department at New York University Libraries; e-mail: laura.mccann@nyu.edu. (C) 2015 Charlotte Priddle and Laura McCann, Attribution-NonCommercial (http:// creativecommons.org/licenses/by-nc/3.0/) CC BY-NC. 
At the 2013 Rare Books and Manuscripts Section (RBMS) Preconference, the authors convened a panel for a seminar on the use of off-site storage for special collections. The seminar consisted of case studies from three geographically diverse Association of Research Libraries (ARL) member libraries that use a variety of systems of off-site storage for their special collections materials. ${ }^{4}$ The program focused on issues of curation, cataloging, preservation, and public access. In the discussion period that followed the presentations, participants offered anecdotal information on the impact of off-site storage on their professional duties. Responses from the audience indicated great interest in the topic but little awareness of the number of institutions using off-site storage for special collections or its potential impact on many aspects of special collections librarianship. The concerns and questions raised following that seminar motivated this article examining the use of off-site storage and its impacts on special collections.

The authors developed a survey for the directors of special collections in ARL member libraries based in the United States to measure the current use of off-site storage by research libraries and to gauge the impact, both positive and negative, on the core activities of special collections located within research libraries. In addition to collecting data about off-site storage that will be useful to research libraries in general, the survey design allows for reporting of observations, thoughts, and opinions in relation to the unique challenges of special collections. Using data drawn from the survey, the authors discuss the varying uses and opinions of off-site storage in relation to issues surrounding the specialized nature of such collections. The collection and analysis of data on the use of off-site storage and its impact on special collections activities is a new contribution to the literature on both off-site storage in research libraries and special collections management.

Off-site storage systems typically follow two main models: the Harvard model and the Automated Storage and Retrieval System (ASRS). The Harvard model uses high, fixed shelving with volumes stored in cardboard trays, with manual retrieval of materials. There is a lag time between user request and access, although some off-site facilities provide on-site reading rooms. These facilities are not designed for rapid retrieval, and they have traditionally been used for low-use circulating materials. The ASRS model stores volumes in metal bins. The bins are retrieved by robotic mechanism, and a manual operator removes the individual volume from the bin. This system minimizes lag time between the user request and access depending on the location of the facility in proximity to the reading room or library. According to a 2007 OCLC report on library storage facilities, 38 of 68 high-density facilities (56\%) used the Harvard model. ${ }^{5}$ The same report noted that there were a total of 15 ASRS facilities used by North American libraries, with the majority constructed between 2004 and $2007 .{ }^{6}$ Although the number of total facilities in use has changed since the date of the report, it nonetheless represents a snapshot of usage within recent years. Regardless of the type of system used, these facilities have similar goals: efficient storage of very large quantities of materials with no direct patron access; separation from traditional library stacks and reading rooms; organization by size rather than call number or collection, and preservation-quality environmental conditions. It should also be noted, however, that there are other, often individualized non-high-density systems in use, including that used by the University of California library system. ${ }^{7}$

\section{ARL Libraries Use of Off-site Storage}

Implementation of off-site storage by ARL member libraries increased substantially during the past three decades according to survey data presented in SPEC kits. ${ }^{8}$ In the 1990 SPEC Kit, Remote Storage: Facilities, Materials Selection and User Services, 50 percent of the 90 survey respondents reported actively using off-site storage. ${ }^{9}$ In the 2006 SPEC 
Kit, Remote Shelving Services, the percentage of libraries using off-site storage increased to 71 percent $(n=85) .{ }^{10}$ Neither these surveys nor the 1999 SPEC Kit survey, Library Storage Facilities, Management, and Services, include any direct questions about the use of off-site storage for special collections, although the 1999 survey featured a question with responses that implies use of off-site by special collections. ${ }^{11}$ Representative documents on off-site storage provided by the survey respondents included in these SPEC Kits infrequently reference special collections materials. ${ }^{12}$

Another 2006 ARL SPEC Kit 296, Public Services in Special Collections, provides data on use of off-site storage for special collections reporting that $51(65 \%)$ of the 79 ARL libraries that responded to the survey use "off-site closed stacks" for storing special collections. ${ }^{13}$ The survey does not query retrieval time for paging materials from offsite or other factors that may indicate how off-site storage impacts public service in special collections.

\section{Literature Review}

Overwhelmingly, the focus of the literature on off-site storage concerns general collections in research libraries, with special collections given attention in only a few case studies. Given the documented use of off-site storage in the 2006 SPEC Kit 296, it is of note that there is little available literature on its impact on special collections. The two available case studies are informative reports and reflections on the use of a high-density off-site storage facility and an ASRS system for archival collections. Mary LaFogg and Christine Weideman's chapter in Library Off-Site Shelving: A Guide for High-Density Facilities speaks to the authors' experiences in the Manuscripts and Archives department at Yale University in 1997, including the movement of 20,000 linear feet of archival material to their shelving facility. ${ }^{14}$ LaFogg and Weideman's chapter provides a case study in planning, reflecting on the experience gained and the problem solving necessary to ensure more streamlined future projects, and offers some practical steps to colleagues planning similar moves. In two related articles, Jacquelyn Sundstrand from the University of Nevada, Reno, also deals with practical aspects of off-site storage for special collections, with her 2008 article focusing on the preparation and planning for moving archival materials, and an update in 2012 describing the experience and knowledge gained from the process. ${ }^{15}$

With the exception of these aforementioned case studies, the published literature on off-site storage for research libraries addresses: the design and management of off-site storage facilities; the selection criteria used to determine the general collections stored off-site; and the range of services provided in connection with off-site storage. In addition, articles address the perceived and realized impact of off-site storage on public service and preservation. Although these publications concern general collections, they may be relevant to special collections and therefore warrant review.

The need for alternative shelving for research collections is not a recent phenomenon. David Block in his 2000 article presents a 2000-year history of remote storage and identifies the trend of research libraries using high-density off-site storage, particularly the Harvard model, as an economic necessity. ${ }^{16}$ In 1999, Ron Chepesiuk examined several ARL member libraries with Harvard model systems and predicted that, despite the projected growth in digital resources, print collections would continue to grow. ${ }^{17}$ In 2002, Chepesiuk and David Weeks remarked on the rise of shared repositories across institutions either geographically connected or via consortial agreement, a trend examined by Ben Walker in 2008 and Fred Heath in 2009. ${ }^{18}$ The significance of shared repositories was noted by the ARL Steering Committee on Transforming Research Libraries in their March 2012 issue brief, which predicted that space concerns, as well as digitization and preservation issues, would lead to a continued rise in shared offsite storage across ARL libraries. ${ }^{19}$ 
In addition to the publications on the design and administration of off-site storage facilities, there are a number of studies on the practical aspects of collection management, particularly selection criteria used for off-site storage, including recent studies by William Joseph Thomas and Daniel L. Schouse, and Simona Tabacaru and Carmelita Pickett. ${ }^{20}$ One participatory model for material selection that may have application for special collections is presented by Amy Lucker, describing working with faculty and students on the selection process within a noncirculating art library to overcome resistance or skepticism in these user populations. ${ }^{21}$ The perceived lack of enthusiasm for off-site storage among users has been noted in many of the articles referenced here, and focused on particularly by Donald Barclay in 2010.22 These concerns focus on retrieval time and delivery, distances, as well as a perceived loss of browsability. While retrieval times and delivery distance are concerns for users of both general and special collections, browsability has never been available to users in traditional closedstacks special collections.

Along with the immediate advantage of creating space for additional acquisitions and possibly new collection development areas, preservation is cited as an immediate benefit of using high-density off-site storage facilities, particularly the Harvard model for both general and special collections. ${ }^{23}$ While the controlled environment in the Harvard model off-site storage facilities promotes preservation, there are risks inherent in high-density storage, particularly for special collections. The findings of two recent studies on fire suppression in high-density off-site storage facilities that were presented at an ALA panel in 2011 described specific risks to boxed archival materials and books, made recommendations as to shelving special collection materials, and offered equipment strategies to minimize damage in the event of a fire. ${ }^{24}$

\section{Methodology}

The authors created a survey to measure the use of off-site storage for special collections materials within research libraries and to study the impact of off-site use on core special collections activities. The decision to select ARL member libraries in the United States as the survey population was based on their similarity in terms of organization, size, and research focus. While most members are university libraries, other institutions whose collections are deemed to have "national significance" can become members. ${ }^{25}$ Although U.S.-based ARL member libraries represent a subset of libraries within the United States, as Martha Kyrillidou states in her article on research library trends, "ARL member libraries are the largest research libraries in North America." ${ }^{26}$ While size alone is not the only significant factor, large research libraries have been quick to adopt off-site storage systems due to their volume count and continued commitment to the acquisition of print materials.

The survey was distributed by e-mail to the directors of special collections at the 108 U.S.-based ARL member libraries on October 31, 2013. E-mail addresses were compiled through professional directories, web searches, and direct contact with ARL member libraries. Two reminder e-mails were sent before the survey closed three weeks after the initial distribution. The e-mail accompanying the survey asked addressees to contact one of the authors if they believed the survey should be redirected, which happened in two cases due to organizational changes (see appendix A: E-mail Message).

The survey, created using the software Qualtrics, consists of closed and open-ended questions (see appendix B: Survey Tool). Survey respondents could choose to bypass most open-ended questions, while the majority of closed questions were required, including the initial question on general use of off-site storage. This flexibility in design aimed to encourage completion of the survey but also resulted in lower response rates for some open-ended questions. 
A positive response to the initial question on general use of off-site storage generated a series of specific questions about its usage, including the frequency of use for special collections materials. Additional open-ended questions asked respondents to elaborate on survey responses and to comment on their experience using off-site storage. Those survey respondents who indicated non-use of off-site storage were queried about planned usage and asked to comment on reasons for non-usage. All respondents who completed the survey were asked if they were willing to participate in a possible follow-up interview.

Survey respondents who indicated use of off-site storage for special collections materials were queried about staff changes and asked to record on a Likert scale the impact of off-site storage on eight core activities within their special collection. These eight core activities - collection development; cataloging and processing; conservation and preservation; public service; teaching and research; management, supervision, and administration; and promotion and outreach-are designated as competency areas for special collections professionals by the Association of College and Research Libraries (ACRL). ${ }^{27}$ These competencies were defined by an RBMS task force and were approved by the ACRL Board in 2008. ${ }^{28}$ These standards set by and for the profession gave respondents the opportunity to assess on an institutional level the effect that off-site storage has had on core professional responsibilities that have a recognized meaning across the profession. Free-form text areas also enabled respondents to comment directly in a more qualitative way on their rankings of impact.

\section{Results}

The survey was completed by 63 of the 108 directors of special collections e-mailed, resulting in a response rate of 58 percent. Respondents spent an average of 10 minutes completing the survey. Results were analyzed in the Qualtrics software and Microsoft

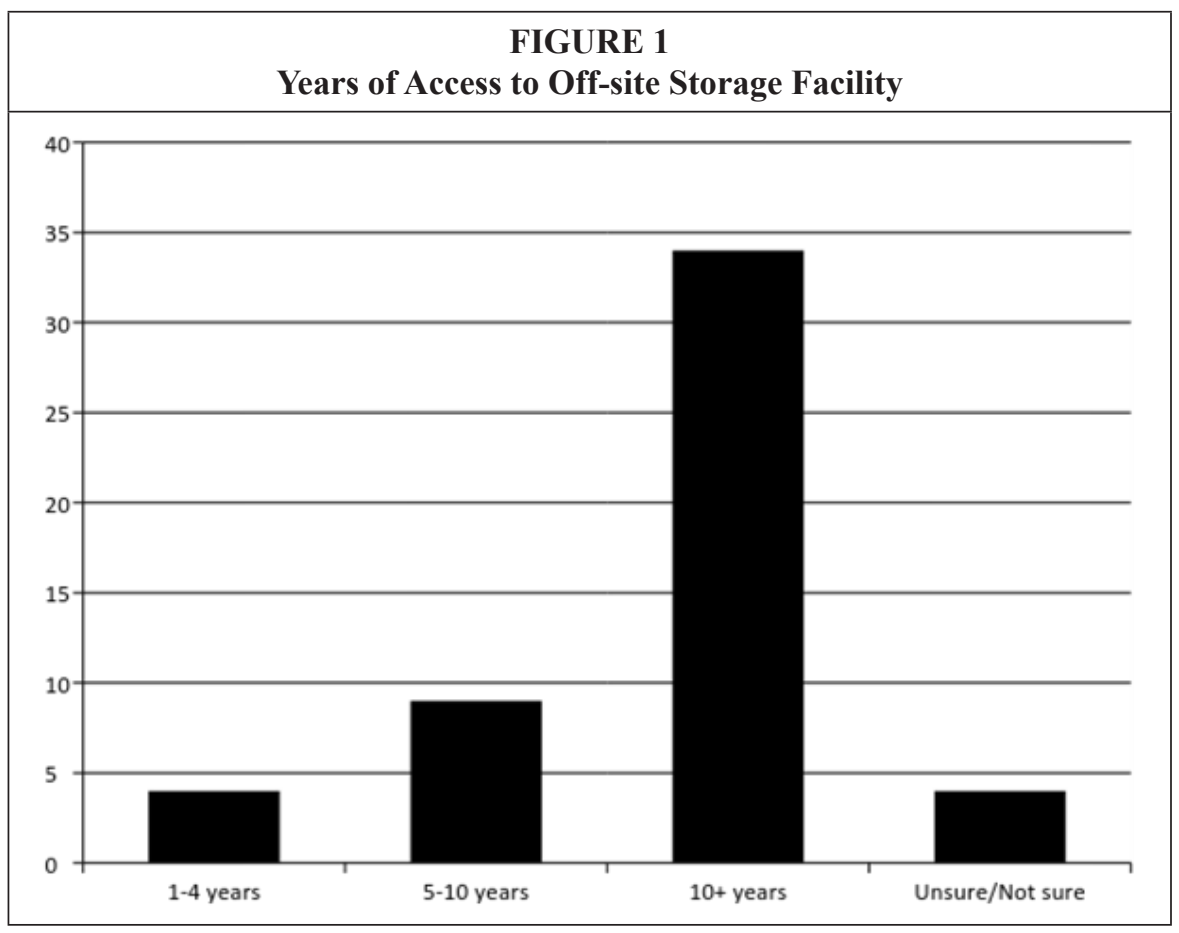


Excel using descriptive statistics. Examination of the results focused first on responses that indicated a current use of off-site storage for their special collections, and then on the results from respondents who indicated that they did not currently use off-site storage for special collections but were considering its use in the future.

Fifty-one of the 63 survey respondents (81\%) reported that they use off-site storage for general library collections. Of these 51 respondents, the vast majority (34, or $67 \%$ ) reported use of off-site storage for over 10 years (see figure 1). Twenty-five respondents (49\%) indicated that they use the Harvard model facility; 2 (4\%) reported use of ASRS facilities, and the remainder indicated "other" in their response. Those who responded "other" were given space to describe their facility in a free-form text box. These descriptions, which were provided by 90 percent of those respondents, indicated the use of either compact or warehouse-style archival shelving.

The vast majority of respondents (47, or $92 \%$ ) who indicated general use of off-site storage within their institution also reported using off-site storage for special collections materials (see figure 2). Only 4 of the question respondents (8\%) indicated no use of off-site storage for special collections materials. All respondents who answered in the affirmative regarding use of off-site storage for special collections were asked to comment on their experience in an open-ended question; 46 of the 47 respondents did so. Staff changes in special collections departments as a result of using (or planning to use) off-site storage were reported by only 2 of the 47 question respondents (4\%). Responses to the optional question querying the types of library materials stored at off-site facilities indicate that the respondents' libraries store a diverse range of materials off-site (see figure 3).

Sharing of off-site storage facilities was reported by 20 respondents (39\%). Of those respondents who use off-site storage for special collections, 19 (40\%) stated that they shared their facility. The types of relationships described by the respondents to a follow-up question reflected the literature on the subject: where sharing occurred, most questioned respondents indicated that the relationship was either one between institutions within the same university system (35\%) or involved consortial agreements between individual institutions $(25 \%)$. The other main relationships described were

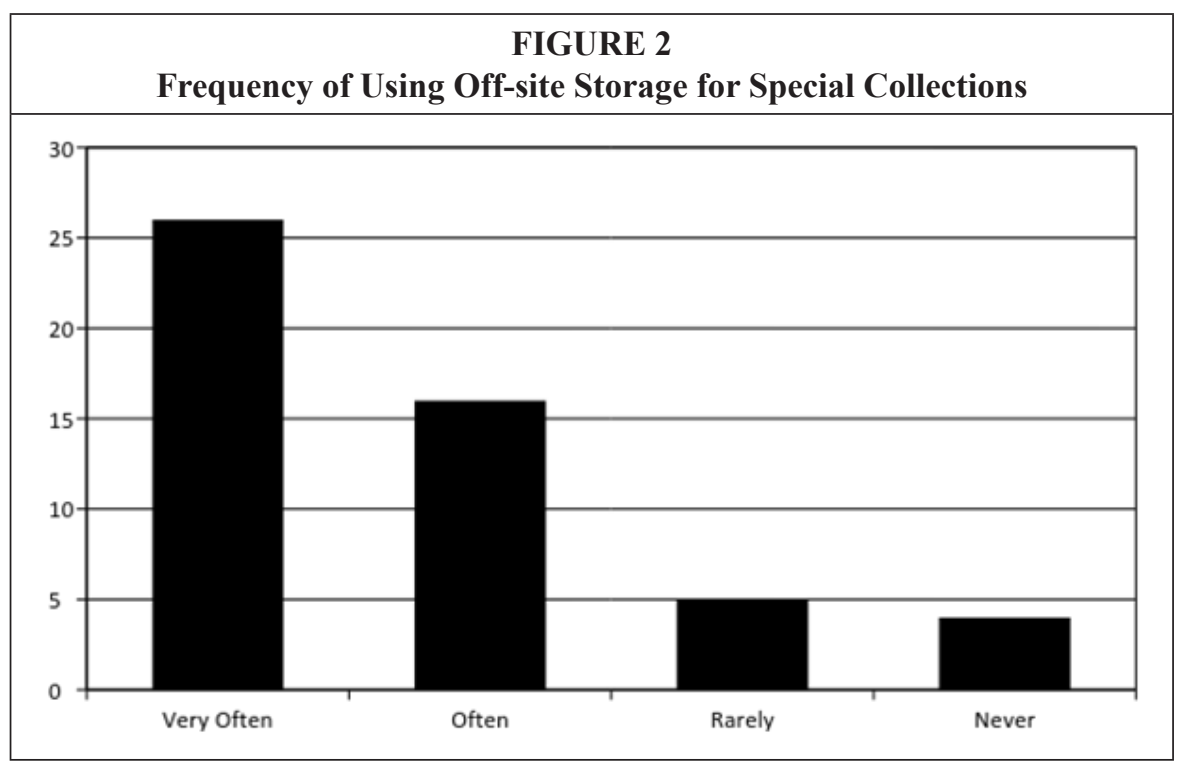




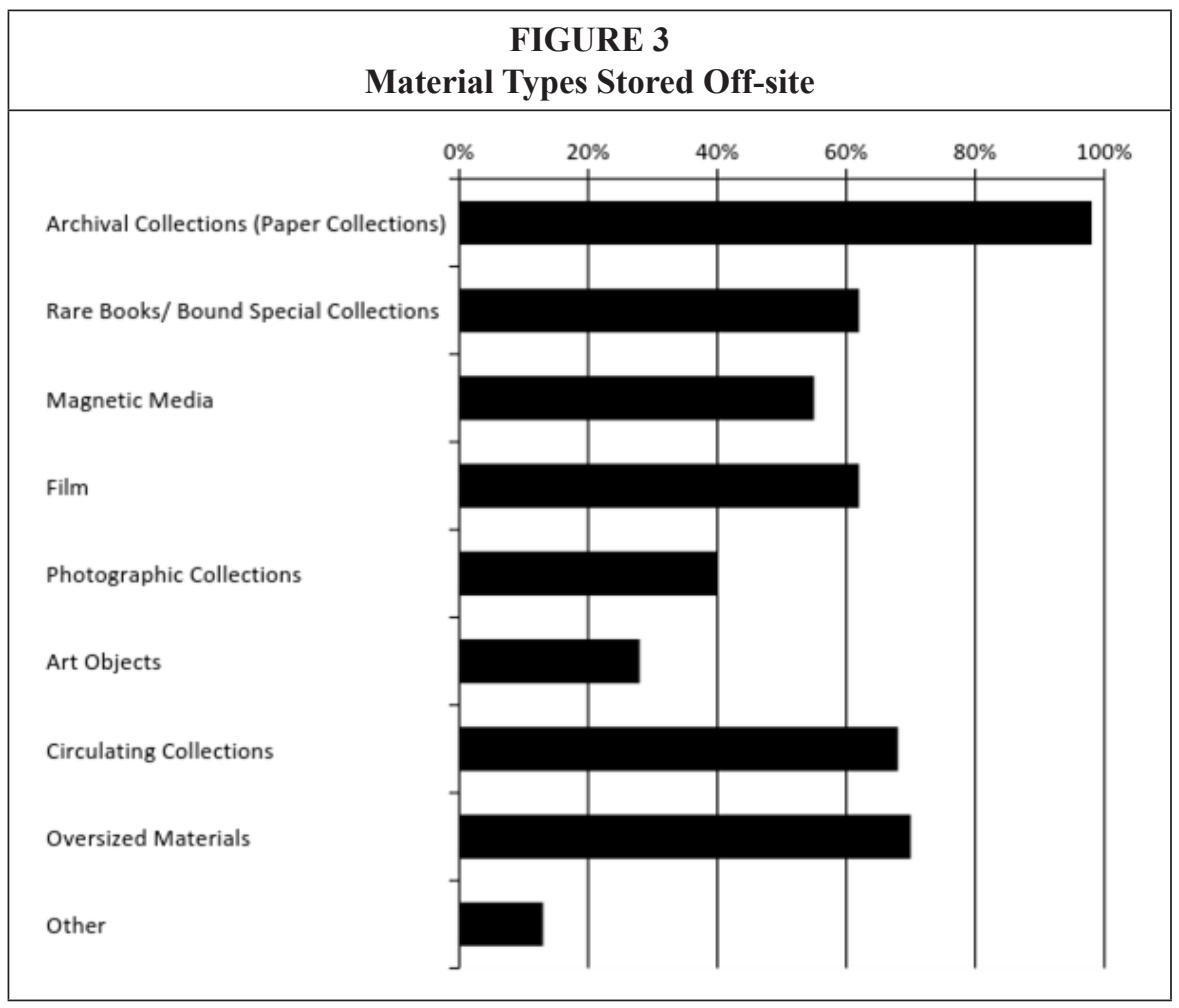

between geographically close institutions individually contracting with an external vendor $(15 \%)$.

The criteria most frequently reported regarding selection of special collections materials for off-site storage was "use (or anticipated use)" (87\%) followed by "size" $(66 \%)$ then "format" $(60 \%)$ and "value" (57\%). Fewer than half of the respondents indicated that condition $(47 \%)$ or level of intellectual control $(40 \%)$ were criteria for selection. (The term "intellectual control" is used as an umbrella term referring to the description of materials, whether through bibliographic or archival methodologies.)

The different methods for material selection were also noted in the comments. Six respondents stated that their facility housed only low-use and/or "medium-rare" materials. ${ }^{29}$ One respondent noted that off-site storage was only used for material that was restricted, such as original film media. Four respondents noted the use of off-site facilities for the storage of unprocessed collections.

The lower priority of intellectual control as selection criteria was reflected in the responses to the survey question about storing unprocessed and/or uncataloged materials off-site. Thirty-nine of the 47 questioned respondents (83\%) indicated that unprocessed and/or uncataloged special collections materials are stored off-site, and 28 percent indicated that unprocessed and/or uncataloged materials are stored off-site very often (see figure 4). Forty-one percent of the 39 responses indicated box- or container-level control for archival collections. Only 14 respondents reported details on intellectual control for print materials. A basic catalog record for individual items was the most frequently reported minimal required level (9 responses). Two respondents described collection-level description for uncataloged books stored off-site, and one respondent stated "no intellectual control" was necessary for off-site storage. 


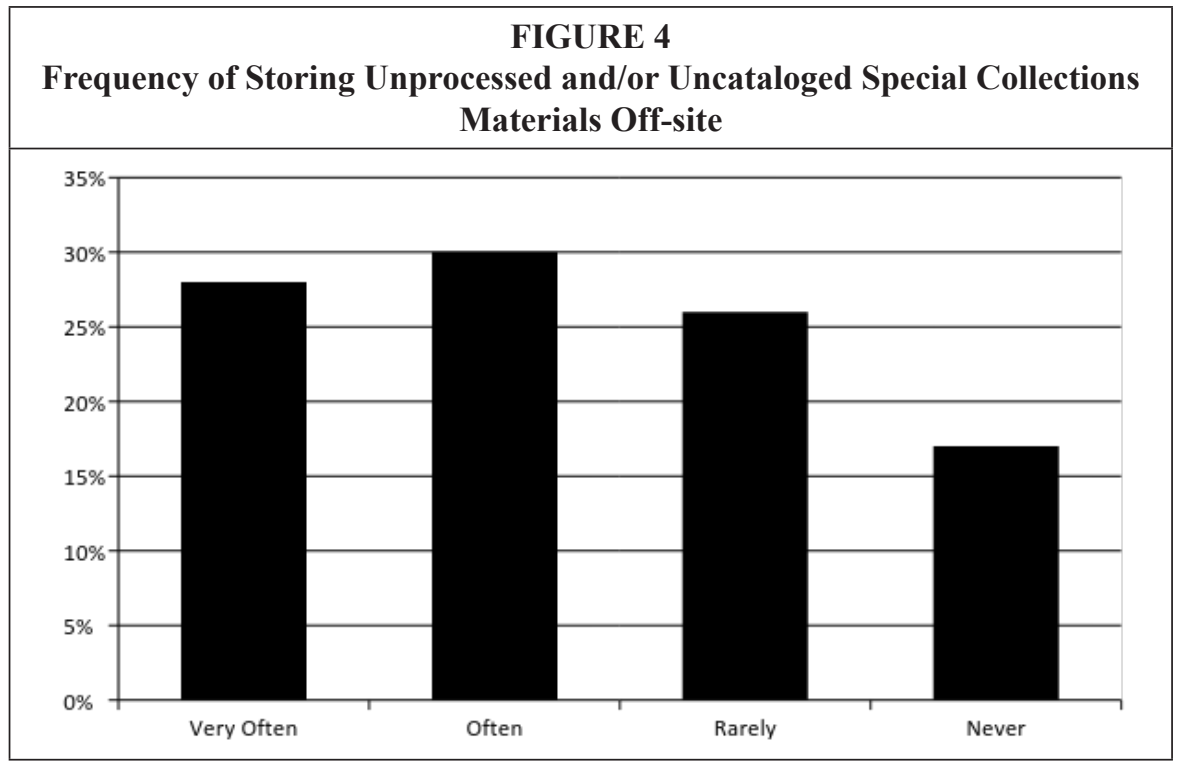

Respondents indicated that the greatest impact to special collections activities was in the area of public service, followed by management, supervision, and administration; conservation and preservation; and cataloging and processing (see figure 5). Public service was the area that received the highest frequency of "significant" responses (14 responses). Of the 46 responses received, 20 referenced public service in their comments. In these comments, respondents particularly noted issues regarding retrieval time for materials and the impact on patron use and satisfaction. The authors noticed a wide variation in retrieval times as indicated by respondents. Of those who specifically

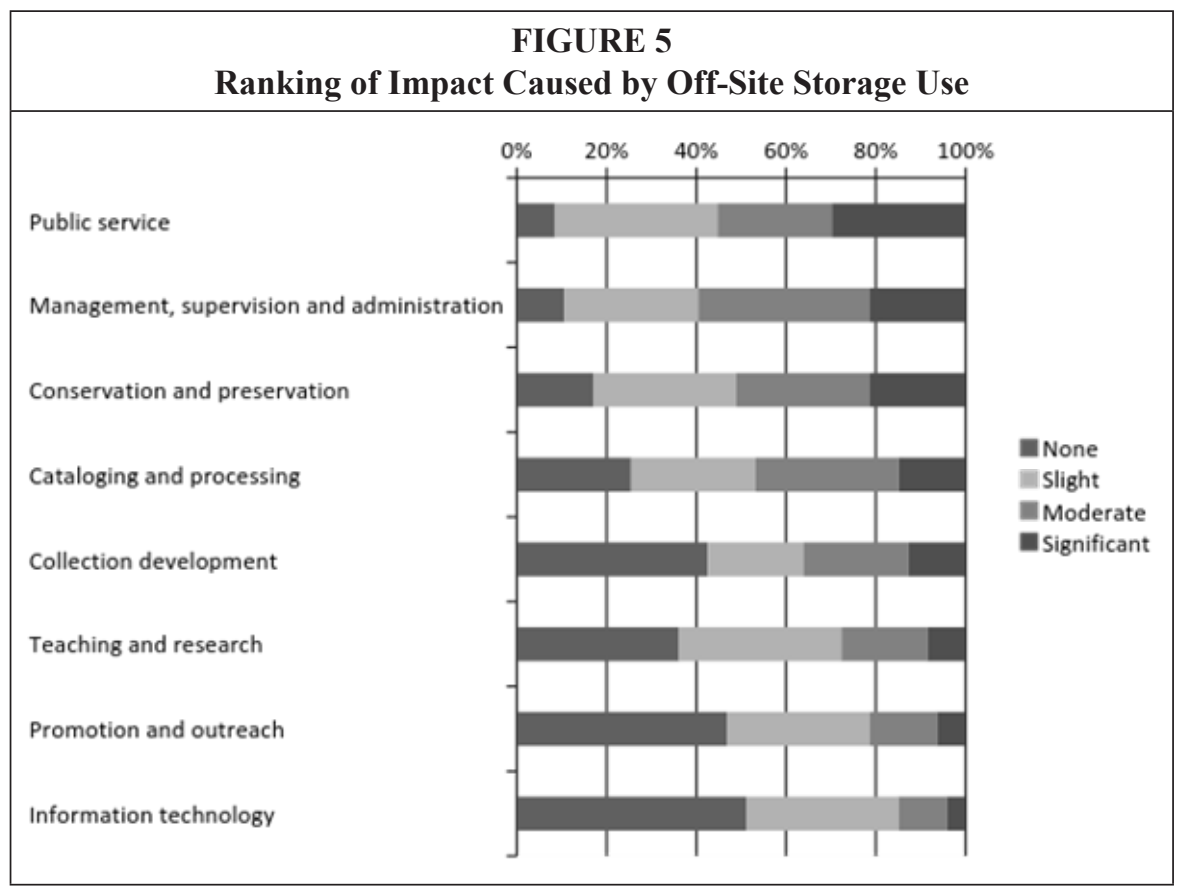


mentioned times, 6 indicated a less than 24-hour delivery time; 8, a delivery window of 24-72 hours; 1 , a weekly delivery; and 1, a monthly delivery.

Respondents who had initially answered that they did not currently use off-site storage for special collections were questioned as to the likelihood of their institution beginning to use such facilities in the future. Of the 12 respondents who had initially stated that they did not currently use off-site storage, 4 respondents (33\%) indicated that they anticipated their institution would use it in the future, within a timeframe of 3-5 years. All respondents gave lack of space as the main motivation, accompanied by continued growth of archival and book collections at a rate that the current space could not accommodate.

The remaining 8 respondents (67\%) who stated that they did not anticipate using off-site storage for special collections in the future were invited to comment. The 7 comments indicated for the most part that on-campus solutions had alleviated space issues, whether involving the construction of an entirely new library building with an integrated ASRS facility on-site or through negotiation with other departments or areas within the library. One respondent noted a lack of funding explicitly as the reason why off-site was not anticipated.

The final question asked of all respondents, regardless of whether they were currently using or planning to use off-site storage for special collections, was about their willingness to participate in a possible brief follow-up interview. Of the 63 respondents who completed the survey, 47 (75\%) answered in the affirmative. These respondents were invited via e-mail in spring 2014 to participate in a telephone interview regarding the results of the initial survey, and 24 interviews were scheduled and completed.

\section{Discussion}

\section{Levels of Usage among Respondents}

The survey results indicated a strong link between the use of off-site storage by special collections departments and their use by the main or circulating collections, with only 8 percent of respondents whose libraries used off-site storage stating that it was never used by special collections. Looking further, over two-thirds of respondents had been using off-site storage for over a decade, and more than 50 percent noted their special collections used it "very often." The data suggest that special collections departments are more likely to use off-site storage for their materials when the facilities had been in use by departments within the same institution for long periods of time. Having internal mechanisms for support and reference may make the decision to use off-site storage for materials other than circulating items easier and may allow special collections to use some of the workflows, such as transit and delivery, created and overseen by colleagues outside special collections.

The other aspect that may underlie the high usage of long-established off-site facilities is the fact that, once space is available, it is difficult not to use it. Five respondents particularly noted that, even if off-site storage was not the ideal solution, it had allowed them to continue to collect, something they would not otherwise have been able to do given space constraints within the home facility. As one individual stated in the free-form comments section: "Without off-site shelving, we would not be able to expand the collections in our current facility," and another, "[h]aving the space, however, has enabled us to continue to collect, which is crucial to our role in supporting research." ${ }^{30}$

While many repositories may be able to keep up with a growth in print materials, the influx of large archival collections, which can figure in the hundreds of boxes, can be impossible to accommodate. As one respondent stated in the follow-up interview: "We would be stuck in terms of acquiring materials if we didn't have it. It has opened 
up opportunities in terms of collecting interests, especially for archives. We have some collections that we wouldn't be able to accommodate without it."

\section{Impacts on Core Special Collections Activities}

As described in the results above, the top four areas of impact, in regard to the eight ACRL Competencies were, in order: public service; management, supervision, and administration; conservation and preservation; and cataloging and processing.

\section{Public Service}

Public service received the most responses for "significant" impact, and this was borne out further in the individual long-form responses commenting on the experience of using off-site storage for special collections. For many, it is apparent that one of the biggest challenges has been communicating logistics around delivery to patrons; 10 respondents reported this as a problem. While the initial survey did not ask specifically about the time lag between request and delivery of off-site materials, in the follow-up interviews all interviewees were specifically asked to comment on the issue of time lags and whether it was the length of time that caused the problem or the simple fact that material was not available immediately. Twelve interviewees stated that the lack of immediate availability of material was the issue; as one said, "The simple existence of a time-lag is the major issue."

As "on-demand" access becomes more universal, the introduction of time lags in materials delivery, particularly for those users who are not frequenters of special collections, can lead to what one respondent described in their comments as "public relations issues." It is apparent from the survey comments and interviews that there exists a division between patrons accustomed to working with special collections, who expect to have to make appointments and plan accordingly, and those "walk-ins" who do not make advance plans and sometimes end up discovering that their materials are not immediately available. Several respondents offered the opinion that undergraduates, who are used to the immediacy of online resources and less aware of or comfortable with the nuances of using special collections, are particularly impacted by materials not being on-site. As one interviewee stated: "[Undergraduates are] used to instant gratification and need it. There is no planning, they wait for the last minute." This observation was echoed in comments throughout the survey and in eight of the interview transcripts, indicating an area of serious concern. Awareness of this potential issue seemed heightened by an understanding of the sometimes daunting nature of special collections: as one interviewee stated, "[undergraduates] are particular constituents of our user base, and are the most heavily impacted. They are already intimidated by special collections, and going there to discover that things are not actually available just makes things worse."

Given the increased visibility of primary resources in teaching at the undergraduate level, a trend noted within the special collections community, several respondents described situations where students changed their research topic because the material was not immediately available, with special collections staff sometimes suggesting on-site alternatives. ${ }^{31}$ Staff also used proactive approaches such as recalling materials in advance that might be the focus of specific undergraduate courses, either at the behest of faculty or through knowledge of existing curricular needs, to mitigate potential problems. Through means such as these, special collections professionals hope to combat any perceived negative impacts of off-site storage and use these incidents as a learning opportunity for undergraduate students, emphasizing the importance of planning research in advance and realizing the potential differences between using online and physical resources. 
Special collections reference services concern not only on-site patrons, but also remote users. ${ }^{32}$ While in-depth research services are not provided by most special collections, basic reference, such as ascertaining how many letters or documents are in a specific file, is not uncommon. Such basic requests can be answered relatively quickly when the material is stored on-site; but when materials are off-site, simple reference requests can take longer than expected to resolve. According to one interviewee, "We feel we need to do more [archival] description for materials that are off-site for remote reference... if we can't tell from the finding aid what is in the collection, we...need to recall it from off-site." Another interviewee wondered about the problem of off-site materials being no longer "visible" to staff, leading to the possibility that materials that could be of use to patrons are not being privileged as much as those stored on-site; "materials stored off-site are out of mind...[materials] that could be timely, important, relevant to the curriculum - we forget we have these whole areas." While loss of browsability may not be an issue for closed-stack special collections patrons, it can be for staff-as having access to materials on-site may help retain institutional memory about collections.

These concerns surrounding public service emphasize the need for outreach and education about the realities of off-site storage to all user communities, particularly undergraduates. As curricular emphasis is placed on the importance of primary resources, more students are becoming aware of the scholarly and research potential in special collections; therefore, it is imperative that communication regarding the means and methods of access are emphasized alongside the importance of the materials themselves. Outreach to other colleagues within the library, including instructional and reference staff, may be a means of ensuring that populations unfamiliar with using special collections are not deterred from using their resources because of confusion regarding access. Further research is necessary to ascertain whether the actual numbers of users impacted reflect the perception, and to what extent, as this was not part of the scope of the initial survey. Given the importance of public service within the profession as a whole, issues of patron dissatisfaction may be more perceived than real. As one of the interviewees stated, "I suspect that the issue is more of a problem in our own minds because we are so public-service oriented."

\section{Management, Supervision, and Administration}

Given the population of the survey, it is perhaps unsurprising that the area of management, supervision, and administration was reported as the second-most impacted area. The integration of new workflows, and the streamlining of these processes in the face of mainly static staffing numbers, necessarily requires oversight and management to ensure adequate forms of control at all points of the process. In the survey, only 4 percent of respondents had seen an increase in staffing levels in special collections as a result of implementing off-site storage. These results reflect general patterns in staffing levels at ARL libraries. ${ }^{33}$

The reported high impact on this area speaks in part to the issue that collections are not simply remaining static in size, but expanding rapidly. If off-site storage has become for many special collections a space that allows them to continue to grow, it also necessitates the creation of complex location management processes and workflows. Research requests for archival collections in particular may number in the tens of boxes; these all need to be accommodated in the on-site space for patron use, often in areas that are already filled to capacity. Add to this the influx of new, unprocessed collections, and the workflow becomes more complicated.

Respondents were aware of the burden that off-site storage had caused for more junior staff responsible for these new processes, who bear the day-to-day brunt of dealing with the in- and outflow of materials; as one respondent commented, "[T]he 
biggest impact is using the same level of staff to maintain two locations instead of one."

Directors of special collections must also negotiate interdepartmentally and, for those using vendor-run systems, externally. The former may include cataloging and/or processing units outside special collections, and particularly preservation/conservation departments. In some institutions, staff from outside special collections are responsible for the transfer and delivery of all materials to and from off-site storage. Relationships between special collections and these departments must be managed to ensure that special collections materials are handled correctly and delivered in a timely fashion. This should involve additional training, strong communication channels, and potential organizational changes. Managing vendor relationships may also involve consortial partners and agreements, adding significant managerial overhead.

\section{Conservation and Preservation}

As seen above, respondents using off-site storage described a variety of storage systems other than the two main high-density models named in the question. The authors noted that those respondents who used these "other" forms of off-site storage were more likely to indicate issues with environmental controls within their facilities and to express concern regarding preservation issues both in terms of the physical storage and in the handling of materials during removal and transit. The major points raised were that non-purpose-built library facilities, such as general commercial warehouses, did not provide the kind of HVAC and other environmental control systems recommended for the storage of special collections materials. Respondents who noted the use of Harvard-style or ASRS models specifically designed for the use and storage of library materials did not voice concerns in the survey about environmental controls.

An issue raised across types of storage systems was the handling of materials by facility staff who were not trained special collections professionals. These concerns were raised directly by three of the respondents in their long-form answers; as one stated, "[W]e have material handling issues with the staff that move the materials - boxes that repeatedly move back and forth do get damaged." In the interviews, four interviewees raised concerns about damage to archival boxes due to excessive travel. Another survey respondent indicated, "We do not have enough staff to cover the off-site space and supervise student workers who pull, reshelve/refile and do basic inventory work." These comments again speak to issues regarding static staffing levels and increased burdens of responsibility, as well as the additional wear and tear that can be caused to collections through transit and handling.

\section{Cataloging and Processing}

The survey offered respondents the opportunity to comment on the intellectual control of material to gain understanding of the level of processing required for sending materials off-site. Given that the majority of respondents noted that some level of control, however minimal, was needed to send materials to an off-site facility, it was not surprising that cataloging and processing were significantly impacted by the use of off-site storage. Levels of intellectual control varied, depending on the internal requirements of each repository and on the materials being sent. This was particularly noticeable in regard to archival collections, with descriptions varying from folder level, to box level, to non-inventoried.

Four respondents noted that their off-site storage included both unprocessed and processed materials, indicating that repositories are using off-site facilities for the storage of collections that go directly off-site and bypass immediate processing, thereby being not accessible to researchers.

To be accessible, collections need some level of bibliographic or archival description. This requirement leads to an inevitable burden falling on those charged with 
creating these records, however minimal. As one respondent stated: "The impact on our Processing unit to get collections ready for permanent transfer to the high density storage unit, given that we have received no additional staffing, has been very challenging." Another respondent noted that the need to barcode materials prior to shipment, particularly for books, also added a layer to internal workflows, particularly as this process can often occur at a point well after the time of original cataloging.

The increase in use of off-site storage within special collections changes internal workflows and processes; as one respondent noted: "[W]hen we started, a folder level inventory for archives was required...we have since sent some things without inventories." This change in patterns of control is again linked to staffing issues and the need to adapt internal workflows to ensure access is possible. Those who reported changing levels of intellectual control in many cases justified the less detailed description because it still enabled access to collections for researchers.

\section{Selection of Materials}

The diversity of decision-making methodologies reported by survey respondents suggests that local priorities drive selection for off-site storage within special collections. Many special collections house not only manuscripts, archives, rare books, ephemera, and art objects, but also less valuable or "medium-rare" books. When the deaccessioning of these items is not appropriate, storing them off-site allows more room for materials that should not travel due to value, condition, or level of use.

Circulating collections use "low-use" as the main criterion for selecting materials for off-site storage. In special collections, use statistics - while indicated in the survey as being the primary selection criterion - cannot be the only one: there are many materials within special collections that may indeed be low-use but that cannot be sent off-site for reasons of fragility, monetary value, rarity, format, or donor status. Decisions are further complicated by the consideration that special collections materials do not circulate in the same way as main stacks materials. Many collections still use call slips or other paper-based forms to page materials. Only recently have registration and circulation systems been designed specifically for special collections, and adoption of them is not universal; consequently, data on use and demographics are often not as detailed as for circulating collections, and predictions of use depend largely on the directors and curators of the repository. ${ }^{34}$

The irony is that, once materials are described and accessible, even predicted low-use collections can become desirable for researchers. As one respondent pointed out: "[S]uddenly a low-use collection becomes fairly well described and easily discovered. We have some materials that we regret having sent to storage because they now get requested a lot." Another respondent similarly stated that since the library began using off-site storage for even minimally processed collections, the amount of material requested from off-site had substantially increased, even for previously unused collections. A problem arises when there is not enough room on-site to permanently recall materials that are being used: in the follow-up interviews, the question was asked as to whether there was enough room on-site for staff to permanently recall collections from storage in such cases: three interviewees stated it could only happen at the expense of something else being sent off-site.

\section{Limitations of Study and Suggestions for Future Research}

After analyzing the results, the authors noted that answers regarding the type of system used and the associated comments indicated differing interpretations of the term. For the authors, "off-site storage" is defined as a high-density purpose-built facility that is not in near proximity to the reading room or curatorial offices of the special collections staff and that may also be geographically remote to the place of use. In retrospect, a definition of the term by the authors at the beginning of the survey, or in the survey 
introduction, would have served to better communicate the authors' understanding and use of it, resulting in more precise results regarding the types of systems used.

Further research on the practical aspects of off-site retrieval methods, particularly the types of transit used (that is to say, use of refrigerated or non-refrigerated trucks) could better inform future planning for off-site storage for special collections, given that material retrieval and transit from the facility to the reading room presents risks. Regular movement between sites increases the risk of damage, both from handling in transit and potential changes in temperature and/or humidity during transit. These are major preservation issues in regard to special collections materials, particularly in regions that experience large fluctuations in seasonal temperature and relative humidity and for fragile media, such as magnetic tapes.

The high response rate suggests to the authors the importance of this topic for special collections, most of which already use or face the prospect of using off-site storage for their materials. The response numbers indicate that further studies that speak to the growth in this area of collection management and control should be conducted and would be beneficial. Additional research on the impacts of off-site storage from the point of view of special collections staff other than directors, such as curators, reference staff, processing archivists, and catalogers, may reveal different insights on the day-to-day realities of integrating off-site facilities in workflows and services. Similarly, in light of the concern around public service and user impact, patron-focused surveys represent an additional important area of research. As more institutions, regardless of size, face the need for their special collections to consider off-site storage, continued study of usage and impact is imperative.

\section{Conclusion}

This study resulted in a significant amount of data and findings supporting what was previously only anecdotally known within the special collections community: that off-site storage is a major part of the current responsibilities of professionals in the field; that it impacts many aspects of varied roles, especially public service; and that its use will only continue to grow in the future. As an initial foray, this article provides a foundation for further investigations into the nuances of the impacts of off-site storage on the profession. Concerns about preservation and public access are of real import; in a service-oriented profession, the latter is of particular significance.

The rise in use of primary resources in university curricula, as well as changes in academic trends, faculty and programs, and expanding areas of research in general, result in both increased acquisition and use of special collections materials. Reflecting on the survey comments and follow-up interviews, it is apparent that, while off-site storage has allowed special collections to continue to expand their holdings, usage of it involves recognized compromises. Despite concerns around public service and preservation, it is important to acknowledge that special collections staff are well aware that their primary responsibilities are to enable the ongoing collection of materials of intellectual and cultural heritage and to give access to these in the best way possible; as one interviewee stated, "Off-site storage really is now just part of special collections at this point. I don't see it going away; as we grow more and more, it is physically impossible to do without it."

\section{Acknowledgements}

This article was informed by a panel convened by the authors at the 2013 RBMS Preconference in Minneapolis titled "Conservation and Curation in the Age of Off-Site Storage." The authors wish to acknowledge the other panelists, Peggy Alexander, Patti Gibbon and Kristen St. John for their participation in the panel and encouragement in the publication of this paper, and Karla Nielsen for moderating the panel. 


\section{APPENDIX A. E-mail Message}

Greetings,

My colleague and I are researching the impact of off-site storage on Special Collections and would appreciate hearing your views on the subject. As the Head of a Special Collections unit at an ARL member library, we believe your input is vital to our research and would appreciate your willingness to take a brief $3-5$ minute survey regarding this topic.

Confidentiality of your responses will be maintained by disassociating your name as well as your institution's name from the research findings. There are no known risks associated with your participation in this research beyond those of everyday life. You can refuse to participate in this survey by deleting this e-mail and any follow-up e-mails.

By clicking on the survey link below and commencing the survey, you are consenting to participate in the survey and affirming you are at least 18 years of age.

If you have any questions about the use of this survey or believe it would be better directed to someone else in your organization, please contact the authors directly via e-mail.

Thank you for your time.

\section{APPENDIX B. Survey Tool}

Does your library use off-site storage?

- $\quad$ Yes (1)

- $\quad$ No (2)

How long has your library used off-site storage?

- $1-4$ years (1)

- 5-10 years (2)

- $10+$ years (3)

- Unsure/Not sure (4)

What type of off-site storage does your library use? (select all that apply)

- Harvard-style high-density storage. (The Harvard model uses high fixed shelving with volumes stored in cardboard trays that are retrieved manually.) (1)

- Automated Retrieval System (ARS). (The ARS model stores volumes in metal bins. The bins are retrieved initially by robotic mechanism; then a manual operator removes the individual volume from the bin.) (2)

- $\quad$ Other (3)

Is your off-site storage facility shared with other institutions?

- $\quad$ Yes (1)

- No (2)

Please describe the relationships that exist between the institutions that share the offsite storage facility (that is, consortium members, libraries within a single university system, geographic proximity, and so on). 
Does your library use off-site for Special Collections storage?

- $\quad$ Very Often (13)

- Often (14)

- $\quad$ Rarely (15)

- $\quad$ Never (16)

Which of the following types of materials does your library house in off-site storage? (Select all that apply)

- Archival Collections (Paper Collections) (1)

- $\quad$ Rare Books/Bound Special Collections (2)

- Magnetic Media (3)

- Film (4)

- Photographic Collections (5)

- Art Objects (6)

- Circulating Collections (7)

- $\quad$ Oversized Materials (8)

- $\quad$ Other (9)

Do you anticipate that your library will use off-site storage for Special Collections in the future?

- Yes (1)

- $\quad$ No (2)

When do you anticipate that your library will begin using off-site storage for Special Collections?

- Within 1 year (1)

- 1-2 years (2)

- 3-5 years (3)

- $5+$ years $(4)$

Please comment on the reasons why your library is planning to use off-site storage for Special Collections.

Please comment on the reasons why your library is not planning to use off-site storage for Special Collections.

Did staffing levels change in Special Collections as a result of using (or planning to use) off-site storage for Special Collections materials?

- $\quad$ Significant Staff Increase (2)

- Modest Staff Increase (3)

- No Increase/No Decrease in Staffing (4)

- $\quad$ Modest Staff Decrease (5)

- $\quad$ Significant Staff Decrease (6)

How many of the following types of positions were created in Special Collections?

- Part-time temporary (enter number of positions below) (1)

- Full-time temporary (enter number of positions below) (2)

- Part-time permanent (enter number of positions below) (3)

- Full-time permanent (enter number of positions below) (4)

- $\quad$ Other (5) 
Are unprocessed and/or uncataloged Special Collections materials stored at your off-site facility?

- $\quad$ Very Often (1)

- Often (2)

- $\quad$ Rarely (3)

- $\quad$ Never (4)

Please describe the minimum level of intellectual control you require for storage offsite for Special Collections.

Which of the following criteria are used to select Special Collections materials for offsite storage? (Select all that apply)

- $\quad$ Size (1)

- Use (or anticipated use) (2)

- $\quad$ Format (3)

- Value (4)

- Condition (5)

- Level of intellectual control (6)

- $\quad$ Other (7)

Please describe what other criteria are used to select Special Collections materials for off-site storage.

Please rate how much impact off-site storage has had on the following areas within your Special Collection:

\begin{tabular}{|l|c|c|c|c|}
\hline & None (1) & Slight (2) & Moderate (3) & Significant (4) \\
\hline Collection development (1) & $\bullet$ & $\bullet$ & $\bullet$ & $\bullet$ \\
\hline Cataloging and processing (2) & $\bullet$ & $\bullet$ & $\bullet$ & $\bullet$ \\
\hline Conservation and preservation (3) & $\bullet$ & $\bullet$ & $\bullet$ & $\bullet$ \\
\hline Public service (4) & $\bullet$ & $\bullet$ & $\bullet$ & $\bullet$ \\
\hline Information technology (5) & $\bullet$ & $\bullet$ & $\bullet$ & $\bullet$ \\
\hline Teaching and research (6) & $\bullet$ & $\bullet$ & $\bullet$ & $\bullet$ \\
\hline $\begin{array}{l}\text { Management, supervision, and } \\
\text { administration (7) }\end{array}$ & $\bullet$ & $\bullet$ & $\bullet$ & $\bullet$ \\
\hline Promotion and outreach (8) & $\bullet$ & $\bullet$ & $\bullet$ & $\bullet$ \\
\hline
\end{tabular}

Please use this space to comment on the experience in your library of using off-site storage for Special Collections, including any impact on core activities.

Are you willing to participate in a (possible) brief follow-up interview?

- $\quad$ Yes (1)

- $\quad$ No (2)

Thank you! Please write your name below.

Please write your e-mail and/or phone number below. 


\section{Notes}

1. See "Preamble," ACRL Code of Ethics for Special Collections Librarians, approved by ACRL in October 2003, available online at http://rbms.info/standards/code_of_ethics.shtml [accessed 31 January 2014].

2. See John N. Berry III, "For All the People of NYPL," Library Journal 138, no. 1 (2013) in response to Ada Louise Huxtable, "Undertaking Its Destruction," Wall Street Journal, December 3, 2012, available online at http://online.wsj.com/article/SB100014241278873237511045781516538 83688578.html [accessed 4 December 2012].

3. Eunice Martin, "Collection Management in Oxford Art Libraries: High-Rise or Deep Six?" Art Libraries Journal 30, no. 2 (2005): 36-40.

4. Charlotte Priddle et al., "Curation and Conservation in the Age of Off-Site Storage: What Does It Mean for Special Collections Librarians and Conservators?" seminar convened at the annual RBMS Preconference, Minneapolis, June 23-26, 2013.

5. Lizanne Payne, Library Storage Facilities and the Future of Print Collections in North America, (Dublin, OH: OCLC, 2007), 9, available online at www.oclc.org/programs/publications/ reports/2007-01.pdf [accessed 21 May 2015].

6. According to the report, 9 ASRS facilities, or 60 percent of the total number, were built between these years. Payne, Library Storage Facilities, 13.

7. The Northern and Southern Regional Library Facilities of the University of California system stores volumes by size double-deep on shelves, with no trays in use. Through adjusting industrial shelving to accommodate large groups of similarly sized materials, space can be maximized and readjusted as collections grow, and retrieval is done manually by staff. Payne, Library Storage Facilities, 9.

8. SPEC Kits "are the result of a systematic survey of ARL member libraries on a particular topic related to current practice in the field. Each SPEC Kit contains an executive summary of the survey results; survey questions with tallies and selected comments; the best representative documents from survey participants." Thomas C. Deardorff and Gordon J. Aamot, SPEC Kit 295: Remote Shelving Services (Washington, D.C.: Association of Research Libraries, 2006), 2.

9. Virginia Steel, SPEC Kit 164: Remote Storage: Facilities, Materials Selection, and User Services (Washington, D.C.: Association of Research Libraries, 1990), 3-4.

10 Deardorff and Aamot, SPEC Kit 295, 18.

11. The survey question "Please check applicable features" included these options that imply use by special collections: "High-security area for rare materials" and "Specialized storage for non-paper items." Jan Merrill-Oldham and Jutta Reed-Scott, SPEC Kit 242: Library Facilities, Management, and Services (Washington, D.C.: Association of Research Libraries, 1999), 6.

12. Examples include documents provided by Harvard on space allocations in their off-site facility of special collections and their process for preparing archival collections for transfer to off-site storage. Steel, SPEC Kit 164, 52; Merrill-Oldham and Reed-Scott, SPEC Kit 242, 97.

13. Florence Turcotte and John Nemmers, SPEC Kit 296: Public Services in Special Collections (Washington, D.C.: Association of Research Libraries, 2006).

14. Mary C. LaFogg and Christine Weideman, "Special Collections," in Library Off-Site Shelving: A Guide for High-Density Facilities, eds. Danuta A. Nitecki and Curtis L. Kendricks (Englewood, Colo.: Libraries Unlimited Inc., 2001): 205-18.

15. Jacquelyn K. Sundstrand, "Placing Manuscript and Archival Collections into an Automated Storage and Retrieval System at the University of Nevada, Reno," Journal of Archival Organization 6, no. 1-2 (2008): 71-80; "Getting to MARS: Working with an Automated Retrieval System in the Special Collections Department at the University of Nevada, Reno," Journal of Archival Organization 9 (2011): 105-17.

16. David Block, "Remote Storage in Research Libraries: A Microhistory," Library Resources $\mathcal{E}$ Technical Services 44, no. 4 (2000): 184-89.

17. Ron Chepesiuk, "Reaching Critical Mass: Off-Site Storage in the Digital Age," American Libraries 30, no.4 (1999): 40-43.

18. David Weeks and Ron Chepesiuk, "The Harvard Model and the Rise of Shared Storage Facilities," Resource Sharing \& Information Networks 16, no. 2 (2002): 159-68; Ben Walker, "Drafting Recommendations for a Shared Statewide High-density Storage Facility: Experiences with the State University Libraries of Florida Proposal," Resources Sharing \& Information Networks 19 (2008): 51-62; Fred M. Heath, "The University of Texas: Looking Forward: Research Libraries in the 21st Century," Journal of Library Administration 49 (2009): 311-24.

19. "Issue Brief: 21st Century Collections: Calibration of Investment and Collaborative Action" (Mar. 10, 2012), task force created by ARL Steering Committee on Transforming Research Libraries, available online at www.arl.org/publications-resources/2021-21st-century-collections- 
calibration-of-investment-and-collaborative-action [accessed 21 May 2015].

20. William Joseph Thomas and Daniel L. Shouse, "Rules of Thumb for Deselecting, Relocating and Retaining Bound Journals," Collection Building 31, no. 3 (2012): 92-97; Simona Tabacaru and Carmelita Pickett, "Damned if You Do, Damned if You Don't: Texas A\&M University Libraries' Collection Assessment for Off-site Storage," Collection Building 32, no. 3 (2013): 111-15. See also Shirley Rais, Michael A. Arthur, and Michael J. Hanson, "Creating Core Title Lists for Print Retention and Storage/Weeding," Serials Librarian 58, no. 1-4 (2010): 244-49; Marianne Stowell Bracke and Jim Martin, "Developing Criteria for the Withdrawal of Print Content Available Online," Collections Building 24, no. 2 (2005): 61-64.

21. Amy Lucker, "Deal with the Devil: A Participatory Model for Off-Site Storage Selection," Art Documentation: Journal of the Art Libraries Society of North America 31, no. 2 (2012): 285-92.

22. Donald A. Barclay, "The Myth of Browsing," American Libraries 41, no. 6-7 (2010): 52-54; Claire Q. Bellanti, "Access to Library Materials in Remote Storage," Collection Management 17, no. 1-2 (1993): 93-103; Dan Hazen, "Selecting for Storage: Local Problems, Local Responses, and an Emerging Common Challenge," Library Resources \& Technical Services 44, no. 4 (2000): 176-83; Bethany B. Sewell, "A Bookless Library, Part II: Managing Access Services with No In-House Collection," Journal of Access Services 10, no. 1 (2013): 51-60.

23 Nitecki and Kendrick, "The Paradox and Politics of Off-site Shelving," in Library Off-Site Shelving: A Guide for High-Density Facilities, 3.

24. Planning for the Worst: Disaster Preparedness and Response in High-Density Storage Facilities" (June 26, 2011), ALCTS-American Library Association 2011 Annual Conference, New Orleans, La. Kristen L.T. Jamison, Technical Report: Fire Protection and Loss Mitigation of High Density Library and Archival Storage (FM Global, 2011). This report is available at no cost from Dave Fuller at FM Global (e-mail: David.Fuller@FMGlobal.com).

25. "Principles of Membership in the Association of Research Libraries," approved February 8, 2001 by ARL Board. Statement adopted February 10, 2006 and edited October 15, 2009, by the ARL Board, available online at www.arl.org/storage/documents/publications/arl-membershipprinciples.pdf [accessed 21 May 2015].

26. Martha Kyrillidou, "Research Library Trends: A Historical Picture of Services, Resources, and Spending," Research Library Issues 280 (2010): 20-27.

27. Rare Book and Manuscript Section, ACRL/ALA Task Force on Core Competencies for Special Collections, Guidelines: Competencies for Special Collections Professionals, approved by ACRL Board, July 1, 2008, available online at www.ala.org/acrl/standards/comp4specollect [accessed 21 May 2015].

28. The RBMS Task Force Committee on Core Competencies in Special Collections Librarianship was recharged in June 2013.

29. "Medium-rare" materials can be described as items such as theses, dissertations, books printed in the mid to late 19th century and 20th century, and materials that are peripheral to the collecting scope of the institution.

30. Other comments included, “...until our on-site storage problems are solved, we'll need to rely ever more heavily on our off-site storage or stop collecting at all," "The option to use off-site storage has greatly expanded our 'stack space'" and "It allows us to take in more materials than on-site storage would allow."

31. See Susan M. Allen, "Rare Books and the College Library: Marrying Undergraduates to Special Collections," RBML 13.2 (1999): 110-19; Steven Escar Smith, "From 'Treasure Room' to 'School Room': Special Collections and Education," RBM 7.1 (Spring 2006): 31-39; Pablo Alvarez, "Introducing Rare Books into the Undergraduate Curriculum," RBM 7.2 (Fall 2006): 94-104; Magia G. Krause, "'It Makes History Alive for Them': The Role of Archivists and Special Collections Librarians in Instructing Undergraduates," Journal of Academic Librarianship 36.5 (Sept. 2010) 401-11; David Mazella and Julie Grob, "Collaborations between Faculty and Special Collections Librarians in Inquiry-driven Classes," portal: Libraries and the Academy 11.1 (2011): 467-87.

32. Turcotte and Nemmers, SPEC Kit 296, 11-17.

33. In the ARL statistics report, member libraries are shown to have seen a 10 percent reduction in staff since 1991, while reporting a higher ratio of students per staff member. Kyrillidou, "Research Library Trends."

34. One of the survey respondents specifically stated: "Selection of special collections materials, which do not circulate and so generate no circulation statistics in our systems, has been problematic." 